\title{
Examining the Relationship between Job Enrichment and Performance: A Case Study of Nurses
}

\author{
Iravane Masoudi Asl ${ }^{1}$, Aslan Nazari ${ }^{2} \&$ Mehdi raadabadi ${ }^{3}$ \\ ${ }^{1}$ Health Services Management Department, School of Management and Economics, Science and Research \\ Branch, Islamic Azad University, Tehran, Iran \\ ${ }^{2}$ Health Management and Economics Research Center, Iran University of Medical Sciences, Tehran, Iran \\ ${ }^{3}$ Health Services Management Research Center, Institute for Futures Studies in Health, Kerman University of \\ Medical Sciences, Kerman, Iran
}

Correspondence: Iravane Masoudi Asl, Science and Research Branch, Islamic Azad University, Tehran, Iran. Tel: 98-912-506-0486. E-mail: masoudi_1352@yahoo.com.com

\author{
Received: December 29, 2014 Accepted: March 17, 2015 Online Published: June 5, 2015 \\ doi:10.5539/ass.v11n18p108 \\ URL: http://dx.doi.org/10.5539/ass.v11n18p108
}

\begin{abstract}
Background: Nurses are the largest group of health care professionals whose performance plays a significant role in improving health care services. One way to increase performance and job satisfaction in nurses is job enrichment. Job enrichment seeks improving performance and employees' satisfaction by broadening the scope of one's performance and giving more opportunities for individual success and growth. The present study aims at investigating the relationship between job enrichment and its dimensions on nurses' performance.

Research Methodology: The present analytical research was done in a public hospital on 160 nurses in Tehran in 2012. The instrument was a questionnaire consisting of two sections of nurses' demographic information and JDS questionnaire with 21 items. The employees' assessment was based on official assessment and self-assessment. The data was analyzed by SPSS.19 and descriptive statistics of mean, standard deviation, frequency, percentage, and comparative tests of qualitative data (Chi-square).

Results: The score of all nurses' performance, whether the formal or official score of performance assessment or the assessment score itself, indicated a high level of performance score and more than half of the nurses had a performance score of 81 to 90 . Among the seven dimensions of job enrichment, the lowest mean was related to job independence and the highest was related to interaction and subsequently. In general, there was no statistically significant importance between job performance and job enrichment $(\mathrm{P}=0.212)$.

Conclusion: Regarding the research limitation (the criterion for assessing nurses' performance was their self-assessment score); it seems that assessing performance score more accurately studies the relationship between these two factors with more precision. In addition, with respect to the deep influence of nursing care on patients' health, utilizing other methods of empowerment for improving nurses' performance is essential in this hospital.
\end{abstract}

Keywords: job enrichment, performance, nurse, hospital, job designing

\section{Introduction}

Specialized and knowledgeable human resource is among the merits of an organization and is the most important competitive advantage and the rarest resource in today's knowledge-oriented economy (Sahoo \& Khess, 2010). Offering different and high-quality products and services, expenses' reduction, creativity, innovation, and increase in competition are advantages of knowledgeable qualitative human resource. Therefore, the business strategies of todays' organizations are necessarily focused on human resources (Zheng, Yang, \& McLean, 2010). Employees' empowerment is one of the effective techniques on the increase of employees' productivity and efficiency and optimum usage of their individual and group potentials, capacities, and abilities in line with organizational goals (He, Murrmann, \& Perdue, 2010).

As a result, organizations need energetic, active, enthusiastic, eager, and motivated employees since they are completely drawn to and engrossed in their jobs and perform their job tasks adequately (Bakker \& Leiter, 2010). Using human resources' potential abilities is a great merit for any organization. In individual efficiency, the 
organization uses a collection of an individual's potential aptitudes, talents, and abilities to progress. It brings about individual growth and alignment and uniformity with the organization by actualizing potential powers and sources and tremendous talents for development and improvement. Thus, the requirement for achieving organizational goals and objectives is effective management of these valuable resources. Today, the principle of organizational efficiency is fulfilled by employees' capabilities. This concept can provide the condition for this aim in a healthy decent environment (Bennet \& Bennet, 2005). Organizational empowerment is equal to empowering employees, i.e. helping them to strengthen their self-confidence and overcome their feeling of helplessness and incapability and giving them motivation to perform their tasks. In empowering, more autonomy, independence, freedom of action and responsibility to make decisions are given to employees (Gagné \& Deci, 2005). In fact, this concept refers to a set of motivational techniques and strategies that seek increasing employees' participation for improving their performance. The main characteristic of employees' empowerment is aligning individual and organizational goals and their congruency (Jerez-Gomez, Cespedes-Lorente, \& Valle-Cabrera, 2005).

One of the methods of employees' empowerment is job enrichment. Job enrichment adds new resources of satisfaction to a job which increases responsibility, independence, and control (Uduji, 2013). The addition of these factors to a job is also called job vertical development. Job enrichment is defined as creating changes in job dimensions (except the rights of its director), job physical conditions, and fundamental tasks in order to increase job satisfaction of an individual who takes the responsibility of executing or performing its tasks (Raza \& Nawaz, 2011). Studies have shown that increasing job enrichment and its dimensions in employees reinforces and boosts their job motivation (Siu et al., 2010). This is so while service sections have a remarkable role in economic growth and higher quality of individuals' life standards and the development of other sections would be impossible without considering service sections (Büyüközkan, Çif̧çi, \& Güleryüz, 2011). Nurses are the largest group of professional employees in health care services who offer care directly to patients and their job conditions influence the consequences related to patients (Zhao et al., 2013). The psychological or mental pressure that is imposed on an individual due to job dissatisfaction can make him/her vulnerable, open and prone to diseases such as heart attack (Almalki, FitzGerald, \& Clark, 2012). On the other hand, professional nursing performance both leads to positive job consequences for nurses and is effective on patients' care processes (Bakker \& Leiter, 2010). Nurses' positive perception from work environment is related to the increase in their recruitment and retention and the decrease in burnout (Hess, DesRoches, Donelan, Norman, \& Buerhaus, 2011). At organizational level, job satisfaction has positive impacts on nurses' retention, decrease in absenteeism, promoting productivity and efficiency, and improving performance (Jerković-Ćosić, Offenbeek, \& Schans, 2012). There are several studies about successful programs of job enrichment which show that job enrichment is an effective means for qualitative improvement of employees' work experience and their proficiency and efficiency at the time of working. Regarding the importance of nursing profession and its effective role on patients' therapy and rehabilitation, empowering the employees of this section of health system, their job vertical development, and increasing their authorities and decision-making roles can increase nurses' job satisfaction and motivation and improve their performance which eventually lead to the promotion of the quality of hospital and healthcare services and subsequently healthcare system, patients and their families, and nurses will benefit from its consequences and outcomes. A nurse's lack of interest to his/her job both reduces work quality and leads to irreversible damages to patients and clients and his/her demoralization and undermining of his spirits and gradually turns him/her to an indifferent depressed person (Weinberg, Luhmann, Bress, \& Hajcak, 2012). With respect to the great importance of healthcare services and its astonishing challenges and changes, healthcare market seems so different every day. Managers and policy-makers of healthcare are attempting to create systems for making hospital employees ready for related posts and jobs in order to make optimum use of their resources. Job enrichment and creating motivation will have determining role in the efficiency and proficiency of human resource at hospitals, creating and increasing value added and success at competition. In this regard, the present study was done with the purpose of studying job enrichment and nurses' performance at hospitals in order to provide a valuable guideline for decision-makers and managers of the health care system for developing human resource and empowering nurses and making changes and variations in this profession and boost nurses' morale and eventually promote the quality of nursing service.

\section{Method}

The analytical present study is an applied or pragmatic one based on its aim and cross-sectional based on its methodology in autumn in 2012 at a public hospital in Tehran. The statistical population includes all 280 nurses at Taleghani Hospital. Among these, 160 nurses were selected based on random sampling. Out of 160 questionnaires that were distributed, 149 questionnaires were completed and returned to the researcher. The 
accuracy of the study based on the volume of the sample was 160 and the first type of error was 0.05 and the difference distinction power of $15 \%$ was equal to $85.5 \%$ which is more than the acceptable conventional level (80\%). The instrument was a questionnaire in 3 sections. The first section includes nurses' demographic information (age, gender, education, work experience, work hours, the main source of income except hospital, and employment at another hospital). In order to assess the job enrichment scores of nurses, JDS Questionnaire with 21 items was used. JDS Questionnaire assesses enrichment at 7 dimensions of skill diversity, task identity, task importance, job independence, and job feedback, feedback from job background factors, and interaction. The main source questionnaire were from study by Hackman and Oldham (Hackman \& Oldham, 1974).

The total enrichment score was obtained from the mean of scores in each dimension. If the score obtained from each dimension is lower than 15 , it means that the job requires enrichment in that dimension. Since there was no access to the official score of nurses' performance assessment, for assessing employees' performance the individuals were asked to report their last year's score if they had been assessed last year; otherwise, they had to assess themselves and give a score from 0 to 7 to themselves. Since the official performance score is out of 100, the amounts or values from 1 to 7 were converted to the scale from 1 to 100 in order to make the data similar or analogous.

The validity of questionnaires was obtained by the experts and their reliability was obtained by Cronbach's alpha to be more than $75 \%$. The data was gathered by field method so that the researcher first gathered the necessary information about the number of nurses and related sections and wards by referring to the metron of the hospital and asked for permission to distribute the questionnaires. Then the researcher himself distributed the questionnaires and gathered them after completion. All the participants' consent was taken orally and they were assured that their information will remain confidential and they can avoid answering any question or item they like to. In addition, all the information was anonymous and gathered confidentially. The data was analyzed by SPSS.19 and descriptive statistics including mean, standard deviation, frequency, percentage, comparative tests of qualitative data (Chi square).

\section{Results}

Table 1. The demographic and job information of the studied employees

\begin{tabular}{|c|c|c|c|}
\hline Variable & Type & Frequency & Percentage \\
\hline \multirow[t]{2}{*}{ Gender } & male & 118 & 79.19 \\
\hline & female & 31 & 20.81 \\
\hline \multirow[t]{6}{*}{ Age } & $20-25$ & 12 & 8.05 \\
\hline & $26-30$ & 29 & 19.46 \\
\hline & $31-35$ & 53 & 35.57 \\
\hline & $36-40$ & 37 & 24.83 \\
\hline & $41-45$ & 10 & 6.71 \\
\hline & $46-50$ & 8 & 5.37 \\
\hline \multirow[t]{3}{*}{ Education } & Pre-bachelor's Degree & 3 & 2.01 \\
\hline & Bachelor's Degree & 126 & 84.56 \\
\hline & Master's Degree & 20 & 13.42 \\
\hline \multirow[t]{7}{*}{ Work Experience } & Less than 5 years & 63 & 42.28 \\
\hline & $6-10$ years & 43 & 28.86 \\
\hline & $11-15$ years & 16 & 10.74 \\
\hline & $16-20$ years & 5 & 3.36 \\
\hline & $21-25$ years & 9 & 6.04 \\
\hline & $26-30$ years & 2 & 1.34 \\
\hline & Unanswered & 11 & 7.38 \\
\hline \multirow[t]{6}{*}{ Work Hours } & Less than 5 hours & 2 & 1.34 \\
\hline & $5-10$ hours & 123 & 82.55 \\
\hline & 11-15 hours & 12 & 8.05 \\
\hline & $16-20$ hours & 2 & 1.34 \\
\hline & 20-24 hours & 0 & 0.00 \\
\hline & Unanswered & 10 & 6.71 \\
\hline Main Source of Income Except & yes & 146 & 97.99 \\
\hline Hospital & no & 3 & 2.01 \\
\hline Employment in Another & yes & 1 & 0.67 \\
\hline Hospital & no & 148 & 99.23 \\
\hline Total & & 149 & 100 \\
\hline
\end{tabular}


79.19 percent of nurses were women and most of them had a bachelor degree (84.56\%). $27.51 \%$ were below 30 years old, $60.4 \%$ were between 31 to 40 , and the rest were over 40 years old. Moreover, $71.14 \%$ had work experience less than 10 years and most of them $(82.55 \%)$ worked between 5 to 10 hours per day (Table 1$)$.

Table 2. The distribution of frequency of the research's samples based in performance assessment score

\begin{tabular}{ccc}
\hline & Frequency & Percentage of frequency \\
\hline $\mathbf{7 0 - 8 0}$ & 1 & 0.67 \\
$\mathbf{8 1 - 9 0}$ & 24 & 16.11 \\
$\mathbf{9 1 - 1 0 0}$ & 4 & 2.68 \\
Sum & 29 & 19.46 \\
Unanswered & 120 & 80.54 \\
Total & 149 & 100 \\
\hline
\end{tabular}

The individuals were asked to report their score if their performance was assessed last year. Out of 149 individuals, only 29 nurses reported their performance scores which are shown in Table 2.

Accordingly, the participants were asked to assess their performance themselves and give a score from 1 to 7 to themselves if they do not know their official score of their performance. 120 individuals who had not answered the previous question gave a score to themselves. All these 120 individuals had scores of 5, 6, or 7 to themselves. Since the scale of performance assessment was out of 100, the scores of 1 to 7 were converted to 1 to 100 for make scores similar, i.e. the score of 7 was considered as 100. To the same proportion, a score of 6 was taken equal to 86 and a score of 5 were considered equivalent to a score of 71 (Table 3 ).

Table 3. The distribution of frequency of the research's samples based on self-assessment score

\begin{tabular}{ccc}
\hline & Frequency & Percentage \\
\hline $\mathbf{7 0 - 8 0}$ & 20 & 13.42 \\
$\mathbf{8 1 - 9 0}$ & 58 & 38.93 \\
$\mathbf{9 1 - 1 0 0}$ & 42 & 28.19 \\
Sum & 120 & 80.54 \\
Unanswered & 29 & 19.46 \\
Total & 149 & 100 \\
\hline
\end{tabular}

Table 4 shows the frequency and mean of each dimension of the 7 dimensions of job enrichment. The lowest degree was related to job independence/autonomy with the mean and standard deviation of $8.08 \pm 3.00$ and the highest mean and standard deviation was related to interaction (18.28 2.29$)$ and subsequently task importance (17.15 \pm 3.24$)$.

The performance of $14.09 \%$ of the studied population was poor, $55.03 \%$ intermediate, and $30.87 \%$ was good.

Table 4. The mean of scores in each dimension of job enrichment

\begin{tabular}{cccccc}
\hline Components & Frequency & The Minimum Score & The Maximum Score & Mean & Standard Deviation \\
\hline Variety of skills & 149 & 7 & 21 & 14.05 & 2.88 \\
Task Identity & 149 & 7 & 21 & 14.32 & 3.17 \\
Task Importance & 149 & 6 & 21 & 17.15 & 3.24 \\
Job Independence & 149 & 3 & 16 & 8.08 & 3 \\
$\quad$ Job Feedback & 149 & 8 & 21 & 14.11 & 3.08 \\
Feedback from Job & 149 & 6 & 21 & 14.76 & 2.91 \\
Background Factors & 149 & 13 & 21 & 18.28 & 2.29 \\
$\quad$ Interaction & & & & & \\
\hline
\end{tabular}

There was no statistically significant relationship between job performance and job enrichment $(\mathrm{p}=0.212) .23 .81 \%$ of individuals had poor performance, $20.73 \%$ had intermediate performance, and $34.79 \%$ had good performance and high job enrichment. Moreover, there was no significant relationship between other dimensions of enrichment and employees' performance (Table 5). 
Table 5. The relationship between job performance and job enrichment score

\begin{tabular}{|c|c|c|c|c|c|c|c|}
\hline & & & Poor & Intermediate & Good & Total & P Value \\
\hline \multirow{2}{*}{\multicolumn{2}{|c|}{ Variety of skills }} & Non-enriched & $21(100)$ & $79(96.34)$ & $44(95.65)$ & $144(96.64)$ & \multirow{2}{*}{0.64} \\
\hline & & Enriched & $0(0)$ & $3(3.66)$ & $2(4.35)$ & $5(3.36)$ & \\
\hline \multirow{2}{*}{\multicolumn{2}{|c|}{ Task Identity }} & Non-enriched & $11(52.38)$ & $58(70.73)$ & $29(63.04)$ & $98(65.77)$ & \multirow{2}{*}{0.257} \\
\hline & & Enriched & $10(47.62)$ & $24(29.27)$ & $17(36.96)$ & $51(34.23)$ & \\
\hline \multirow{2}{*}{\multicolumn{2}{|c|}{ Task Importance }} & Non-enriched & $5(23.80)$ & $23(28.04)$ & $12(26.08)$ & $40(26.84)$ & \multirow{2}{*}{0.917} \\
\hline & & Enriched & $16(76.20)$ & $59(71.96$ & $34(73.92)$ & $109(73.16)$ & \\
\hline \multirow{2}{*}{\multicolumn{2}{|c|}{ Job Independence }} & Non-enriched & $21(100)$ & $81(98.80)$ & $45(98.00)$ & $147(98.00)$ & \multirow{2}{*}{0.765} \\
\hline & & Enriched & $0(0)$ & $1(1.20)$ & $1(2)$ & $2(2.00)$ & \\
\hline \multirow{2}{*}{\multicolumn{2}{|c|}{ Job Feedback }} & Non-enriched & $15(71.42)$ & $56(68.29)$ & $31(67.39)$ & $102(68.45)$ & \multirow{2}{*}{0.946} \\
\hline & & Enriched & $6(28.58)$ & $26(31.71)$ & $15(32.61)$ & $47(31.55)$ & \\
\hline \multirow{2}{*}{$\begin{array}{l}\text { Feedback } \\
\text { Factors }\end{array}$} & \multirow[t]{2}{*}{ Background } & Non-enriched & $13(61.9)$ & $53(64.63)$ & $27(58.70)$ & $93(62.41)$ & \multirow{2}{*}{0.80} \\
\hline & & Enriched & $8(38.10)$ & $29(35.37)$ & $19(41.30)$ & $56(37.59)$ & \\
\hline \multirow{2}{*}{\multicolumn{2}{|c|}{ Interaction }} & Non-enriched & $2(9.52)$ & $17(20.74)$ & $5(10.86)$ & $24(16.1)$ & \multirow{2}{*}{0.234} \\
\hline & & Enriched & $19(90.48)$ & $65(79.26)$ & $41(89.14)$ & $125(83.9)$ & \\
\hline \multirow{2}{*}{\multicolumn{2}{|c|}{ enrichment }} & Non-enriched & $16(76.19)$ & $65(79.27)$ & $30(65.21)$ & $111(74.5)$ & \multirow{2}{*}{0.212} \\
\hline & & Enriched & $5(23.81)$ & $17(20.73)$ & $16(34.79)$ & $38(25.5)$ & \\
\hline
\end{tabular}

\section{Discussion}

The performance scores of all nurses, whether the official score of performance assessment or self-assessment score, show a high level of performance score and more the performance score of more than half of the nurses was between 81 and 90 . These results can show the very high performance of nurses or the inaccuracy of the assessment method or accuracy of performance assessment. Studies by Griffin showed that performance assessments are poor in most investigations (Sekhar, 2002).

Regarding job enrichment, three fourth of the sample had low job enrichment. Among the 7 dimensions of job enrichment, the lowest mean was related to job independence and the highest mean was related to interaction and subsequently task importance, and feedback from job background factors. This result is to some extent influenced by nursing job which is of great importance due to dealing with people's health and requires high interaction although it seems that job independence is one of the subjects to which attention should be paid for enriching this profession. The results of this research show that there is a significant correlation between feedback from job background factors and job feedback and also between interaction and the three factors of task identity, task importance, and job independence. However, no significance correlation was observed between other dimensions. This lack of correlation between dimensions of job enrichment is reported in other studies. The study by Feder showed a significant correlation between skill variation and task importance and no significant correlation between other 7 dimensions of enrichment since these dimensions represent different dimensions or aspects of any job which do not have correlation and relationship (Feder, 1999); however, some studies showed correlation between dimensions of enrichment. In Brief and Uduji's study, the calculated correlation coefficients between 4 dimensions of job and the individual and organizational results and consequences were significant except the correlation coefficient between task identity and job motivation. Hackman and Lawler reported the correlation between these dimensions in a range between 0.06 for feedback and freedom of action to 0.67 for freedom of action and task variety (Hackman \& Lawler, 1971). Contradictory results about correlation between job enrichment dimensions may be because of no clear relationship between classifications of job enrichment dimensions since there are no clear boundaries between job characteristics. Furthermore, there is still no appropriate instrument for accurate assessment of these dimensions. White believed that a relationship between job dimensions depends on the studied sample and conditions. This lack of correlation may be related to inaccuracy of measuring dimensions of job enrichment. Stone believes that standard instruments for assessing job characteristics in line with assessing the number and identity of different job dimensions which are perceived by people have not been so successful.

There was no statistically significant relationship between job performance and job enrichment. Different studies show different patterns of the impact of the relationship between job enrichment and job performance. In a study by Hackman and Lawler, it was shown that job enrichment has a relationship with employees' satisfaction, performance, and presence at work place (Hackman \& Lawler, 1971). Herzberg's studies in 1969 (Herzberg, 1986) and 13 consecutive researches by Lakniz (Lawler III, Hackman, \& Kaufman, 1973) show the potential impact of job enrichment on job performance. Adam Grant researches' demonstrated a significant relationship 
between job importance and job performance (Grant, 2008). The researches by Yen also showed that the richer the more personal satisfaction and the less likely job turnover or quittance will be (Lin, Yeh, \& Lin, 2007); although there are other studies that have not shown the association or relationship between job enrichment and job performance. Lawler found that job dimensions and characteristics and the obtained outcomes cannot have a remarkable effect on job satisfaction and promotion of work motivation (Lawler, 2000). Valerie Millette's investigation showed that job characteristics of degree of independence, satisfaction, and performance are related and the stimulant of independence functions as a moderator variable in the relationship between job characteristics and satisfaction. In fact, the results in Millette's research showed that performance is directly related to job characteristics, but performance has no relationship with motivated (Millette \& Gagné, 2008). The results of the research by Fredrick Morgeson showed that job scope has positive relationship with independence, cognitive ability, job skills, and an individual's performance but the relationship between independence/autonomy with performance is very poor and unstable and this relationship is very complicated and influenced by other factors as well (Morgeson, Delaney-Klinger, \& Hemingway, 2005). These contradictory results were also considered in the previous studies. Griffin showed that job enrichment has diverse effects on performance (Griffin, 1982). The reasons for the observed differences can be rooted in the following factors:

- Job enrichment can be effective when new methods of attitude towards job relationships are created in employees (Lawler III et al., 1973).

- Job enrichment must observe, obey, and be able to accept and adapt to changes.

- Job enrichment process should be associated and accompanied by the increase in information, learning and employees or staff's skills.

Therefore, when empowerment is not associated with or accompanied by job enrichment, it cannot result in increased efficiency and productivity. In addition, other factors such as job durability or employment permanence, goal setting, and social patterns, community involvement, the judgment or verdict of management, disagreement and contradiction with non- enriched groups, employees' lack of involvement and participation in the designing process, the need for high growth, and strong religious beliefs make the effect of enrichment on performance complex. Moreover, since this study was conducted at a hospital in Tehran, urbanization factor was also effective in reducing the impact of job enrichment. Previous studies have shown that people in urban areas compared to rural areas show less reaction and response to job enrichment (Hackman \& Lawler, 1971).

In summary, based on the results of this study, it can be concluded that the degree of nurses' job enrichment is low at Taleghani Hospital although they have high job performance. There is no significant relationship between job enrichment and job satisfaction and job performance of nurses.

\section{Acknowledgments}

The Authors would like to thank all participants for their kind cooperation with the researchers in collecting the data.

\section{References}

Almalki, M. J., FitzGerald, G., \& Clark, M. (2012). The relationship between quality of work life and turnover intention of primary health care nurses in Saudi Arabia. BMC health services research, 12(1), 314. http://dx.doi.org/10.1186/1472-6963-12-314

Bakker, A. B., \& Leiter, M. P. (2010). Work engagement: A handbook of essential theory and research. Psychology Press.

Bennet, D., \& Bennet, A. (2005). The rise of the knowledge organization. Handbook of knowledge management, $1,5-20$.

Büyüközkan, G., Çifçi, G., \& Güleryüz, S. (2011). Strategic analysis of healthcare service quality using fuzzy AHP methodology. Expert Systems with Applications, 38(8), 9407-9424. http://dx.doi.org/10.1016/j.eswa. 2011.01.103

Feder, I. (1999). Customized Job Enrichment and Its Effect on Job Performance. Universal-Publishers.

Gagné, M., \& Deci, E. L. (2005). Self - determination theory and work motivation. Journal of Organizational behavior, 26(4), 331-362. http://dx.doi.org/10.1002/job.322

Grant, A. M. (2008). The significance of task significance: Job performance effects, relational mechanisms, and boundary conditions. Journal of applied psychology, 93(1), 108. http://dx.doi.org/10.1037/0021-9010.93. 1.108 
Griffin, R. W. (1982). Task design: An integrative approach. Scott, Foresman and Company Glenview, Illinois.

Hackman, J. R., \& Lawler, E. E. (1971). Employee reactions to job characteristics. Journal of applied psychology, 55(3), 259. http://dx.doi.org/10.1037/h0031152

Hackman, J. R., \& Oldham, G. R. (1974). The Job Diagnostic Survey: An instrument for the diagnosis of jobs and the evaluation of job redesign projects.

He, P., Murrmann, S. K., \& Perdue, R. R. (2010). An investigation of the relationships among employee empowerment, employee perceived service quality, and employee job satisfaction in a US hospitality organization. Journal of Foodservice Business Research, 13(1), 36-50. http://dx.doi.org/10.1080/1537 8021003595947

Herzberg, F. (1986). One more time: how do you motivate employees? New York: The Leader Manager, 433-448.

Hess, R., DesRoches, C., Donelan, K., Norman, L., \& Buerhaus, P. I. (2011). Perceptions of nurses in magnet ${ }^{\circledR}$ hospitals, non-magnet hospitals, and hospitals pursuing magnet status. Journal of Nursing Administration, 41(7/8), 315-323. http://dx.doi.org/10.1097/NNA.0b013e31822509e2

Jerez-Gomez, P., Cespedes-Lorente, J., \& Valle-Cabrera, R. (2005). Organizational learning capability: a proposal of measurement. Journal of Business Research, 58(6), 715-725. http://dx.doi.org/10.1016/j.jbusres. 2003.11.002

Jerković - Ćosić, K., Offenbeek, M., \& Schans, C. (2012). Job satisfaction and job content in Dutch dental hygienists. International journal of dental hygiene, 10(3), 155-162.

Lawler, E. E. (2000). Rewarding excellence. Pay Strategies for the New Economy.

Lawler, E. E. III, Hackman, J. R., \& Kaufman, S. (1973). Effects of Job Redesign: A Field Experiment1. Journal of Applied Social Psychology, 3(1), 49-62. http://dx.doi.org/10.1111/j.1559-1816.1973.tb01294.x

Lin, B. Y.-J., Yeh, Y.-C., \& Lin, W.-H. (2007). The influence of job characteristics on job outcomes of pharmacists in hospital, clinic, and community pharmacies. Journal of medical systems, 31(3), 224-229. http://dx.doi.org/10.1007/s10916-007-9059-y

Millette, V., \& Gagné, M. (2008). Designing volunteers' tasks to maximize motivation, satisfaction and performance: The impact of job characteristics on volunteer engagement. Motivation and Emotion, 32(1), 11-22. http://dx.doi.org/10.1007/s11031-007-9079-4

Morgeson, F. P., Delaney-Klinger, K., \& Hemingway, M. A. (2005). The importance of job autonomy, cognitive ability, and job-related skill for predicting role breadth and job performance. Journal of applied psychology, 90(2), 399. http://dx.doi.org/10.1037/0021-9010.90.2.399

Raza, M., \& Nawaz, M. (2011). Impact of job enrichment on employees' job satisfaction, motivation and organizational commitment: Evidence from public sector of Pakistan. European Journal of Social Sciences, 23, 220-226.

Sahoo, S., \& Khess, C. R. (2010). Prevalence of depression, anxiety, and stress among young male adults in India: a dimensional and categorical diagnoses-based study. The Journal of nervous and mental disease, 198(12), 901-904. http://dx.doi.org/10.1097/NMD.0b013e3181fe75dc

Sekhar, S. C. (2002). Human resource management in hospitals. Managing a Modern Hospital, 141-173.

Siu, O.-1., Lu, J.-f., Brough, P., Lu, C.-q., Bakker, A. B., Kalliath, T., . . Lo, D. (2010). Role resources and work-family enrichment: The role of work engagement. Journal of Vocational Behavior, 77(3), 470-480. http://dx.doi.org/10.1016/j.jvb.2010.06.007

Uduji, J. I. (2013). Job Enrichment: A Panacea to the Problem of the Demotivated Marketing Executives in the Banking Industry in Nigeria. European Journal of Business and Management, 5(13), 99-106.

Weinberg, A., Luhmann, C. C., Bress, J. N., \& Hajcak, G. (2012). Better late than never? The effect of feedback delay on ERP indices of reward processing. Cognitive, Affective, \& Behavioral Neuroscience, 12(4), 671-677. http://dx.doi.org/10.3758/s13415-012-0104-z

Zhao, P., Chen, F. J., Hui Jia, X., Lv, H., Cheng, P. P., \& Zhang, L. P. (2013). The validation and application of the Chinese version of perceived nursing work environment scale. Journal of clinical nursing, 22(13-14), 1827-1832. http://dx.doi.org/10.1111/jocn.12229

Zheng, W., Yang, B., \& McLean, G. N. (2010). Linking organizational culture, structure, strategy, and 
organizational effectiveness: Mediating role of knowledge management. Journal of Business Research, 63(7), 763-771. http://dx.doi.org/10.1016/j.jbusres.2009.06.005

\section{Copyrights}

Copyright for this article is retained by the author(s), with first publication rights granted to the journal.

This is an open-access article distributed under the terms and conditions of the Creative Commons Attribution license (http://creativecommons.org/licenses/by/3.0/). 